\section{UK union attacks GMAG bureaucracy}

THE Association of University Teachers (AUT) in the UK is worried about the paperwork its members could face if the Genetic Manipulation Advisory Group's (GMAG) plans to include selfcloning experiments within its remit (see below) are adopted. Three AUT representatives expressed their concern to members of parliament last week when they gave evidence to the House of Commons Select Committee on Science and Technology which is currently examining genetic engineering.

Dr David Sherratt of Sussex University, one of the AUT representatives, explained to Nature after the meeting that most of the concern centres on the interpretation of part of the document published in Nature last year ( 9 November, page 104) on proposed new guidelines for the UK. The document states that laboratories intending to do self-cloning experiments should provide "a block notification" of the experiments to be done over a year, an undertaking to work in category $1^{*}$ and a retrospective "detailed log of all experiments carried out".

The latter point causes Dr Sherratt most concern. "In our laboratory", he says " $12-15$ of us are using these techniques (cloning $E$. coli genes into $E$. coli organisms) every day." Providing GMAG with a detailed log of all such experiments (up to 1,000 in a year) could make the amount of bureaucracy the laboratory has to deal with "absolutely enormous", he claims. a single sentence on each experiment will satisfy GMAG or whether it will require short papers. "It all depends on what they want", says Dr Sherratt.

Under the Williams guidelines, which still operate, his laboratory, together moment notify GMAG of self-cloning debating. As yet, however, no-one knows whether with most others, does not at the

experiments. Scientists have generally interpreted GMAG's definition of genetic manipulation as excluding selfcloning. During 1978, however, the Medical Research Council (MRC) indicated that self-cloning experiments should be considered by GMAG. It suddenly started to make the award of some grants for work involving selfcloning experiments conditional on those experiments being notified to GMAG. GMAG went along with this. Prior to 1978 , it would seem that the MRC and GMAG had agreed with scientists that these experiments did not count as genetic manipulation.

The trouble is that GMAG's definition of genetic manipulation is ambiguous with regard to self-cloning, so it could be argued that both the MRC's interpretation and that of the scientists are correct. Even GMAG admits that it is ambiguous. Its remit is defined as: "the formation of new combinations of heritable material by the insertion of nucleic acid molecules produced, by whatever means, outside the cell, into any virus, bacterial plasmid or other vector system so as to allow their incorporation into a host organism in which they do not naturally occur but in which they are capable of continued propagation". The chief difficulty, says Dr Sherratt, arises in the meaning assigned to "they" in the phrase "in which they do not naturally occur". If it refers to the "new combinations", then all self-cloning experiments are included in the guidelines. If, on the other hand, it refers to the "nucleic acid molecules", as most scientists have assumed it does, then all self-cloning experiments are exempt from regulation. This is the point that GMAG has recently been

Judy Redfearn

\section{GMAG wants self-cloning notification}

IN a controversial decision last week, Britain's Genetic Manipulation Advisory Group (GMAG) has opted to include self-cloning in its definition of "genetic manipulation", but to slacken its notification procedures for such experiments. However GMAG has not yet issued a formal statement of its new views, and will not do so until after 16 March, when it meets to decide a final form of words.

That meeting will require decisions on three crucial issues: first, what containment conditions will be required for self-cloning (and related experiments); second, what experiments to include in this slackened category; and third, what notification procedures to demand.
At present, GMAG feels that "good microbiological practice" will be sufficient, somewhat more relaxed than the present Category 1; that three or four systems could be included, such as $E$. coli in $E$. coli, and experiments likely to be undertaken in teaching; and that the notification should be more of a formality than a chore. But precisely where the group stands on these matters is not decided.

For comparison the revised guidelines of the US National Institutes of Health clearly exempt from any control all self-cloning experiments, experiments involving donor-host pairs that naturally exchange DNA, and some cloning experiments with viral DNA in viral vectors. Robert Walgate

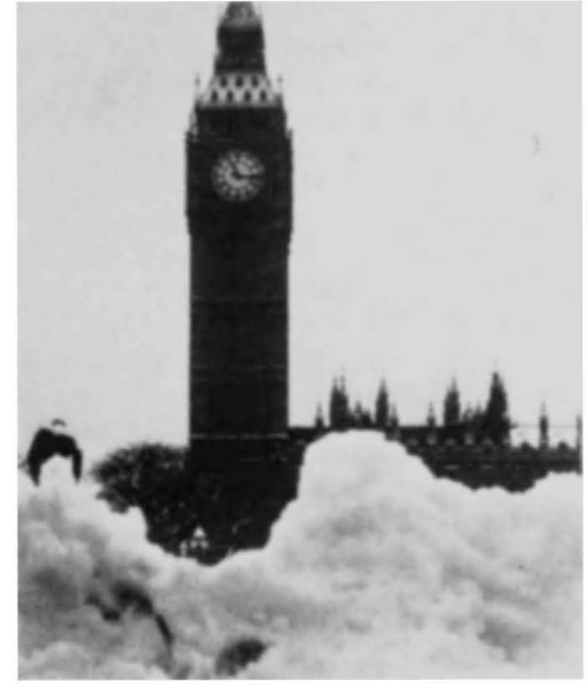

Britain snowed up, January 1979

\section{World climate conference turns to the weather}

IT is the short term variability of climate-to most people, year-to-year variation in 'the weather'-that matters most, not the longer term 'climatic' variation with which some (perhaps especially some of the environmentalists) are more deeply concerned. This is a first conclusion to be drawn from the "Conference of Experts on Climate and Mankind" convened recently in Geneva by the World Meteroological Organisation.

Certainly, the effects of short-term variability are serious enough. It was one such phenomenon, the Sahel drought of 1968-73, which in fact brought the need for some sort of climate conference to the fore.

Figures given by Robert Kates of Clark University indicated that between them floods, tropical cyclones and drought cost the world a good $\$ 30$ billion each year, claiming the lives of some 250,000 people, $95 \%$ of them citizens of the Third World. While the absolute costs of these disasters are many times greater in developed than in underdeveloped countries, in terms of GNP the situation is reversed: "Climatic hazard impacts poor countries 20-30 times the rate of rich countries," Kates suggests.

While the need for research on short-term variability was recognised as the immediate research priority, there was inevitably a great deal of discussion at the meeting of the possibility (rather than the probability) of medium term changes. This brought up the debate between the "ice age" prophets, and those who see the danger of a globalwarming as the more immediate threat. 